No case-control study is ever perfect; in our study we could control as closely as possible for all major prognostic variables. As this was done the findings suggest that severe life stress may be an additional determinant of prognosis in breast cancer.

AMANDA RAMIREZ

T CRAIG

J P WATSON

IAN $S$ FENTIMAN

$M$ A RICHARDS

W R S NORTH

R D RUBENS

Imperial Cancer Research Fund Clinical Oncology Unit and Department of Psychiatry, Guy's Hospital,

London SE1 9RT

1 Millis RR. Correlation of hormone receptors with pathological features in human breast cancer. Cancer 1980;46:2869-71.

2 Fisher B, Richmond C, Fisher ER, et al. Relative worth of estrogen or progesterone receptor and pathological characteristics of differentiation as indicators of prognosis in node negative breast cancer patients: findings from national surgical adjuvant breast and bowel projects protocol B-06. $7 \mathrm{Clin}$ Oncol 1988;6:1076-87.

3 Valagussa P, Bonadonna G, Veronosi U. Patterns of relapse and survival following radical mastectomy. Cancer 1978;41:1170-8. Haagensen CD. Diseases of the breast. 3rd ed. Philadelphia: W B Saunders, 1986.

\section{Autoimmunity: a risk factor for allosensitisation to blood products?}

SIR, - We thank Dr M Contreras ${ }^{1}$ for clarifying certain points in our paper on multiple autoimmunity and allosensitisation to blood products. We agree that the measures suggested are adequate for most cases of allosensitisation and for most patients with single entity autoimmune disease.

Nevertheless, our case series deals with a smaller group of patients with multiple autoimmune diseases (but not autoimmune haemolytic anaemia) who have shown an ability to react frequently to weak (self) immunogens. Alloantigens are bound to carry a high risk of sensitisation in this group. Transfusion is best avoided in these patients, but this is not always possible.

Alloabsorption techniques ${ }^{3}$ or the "polybrene" technique ${ }^{4}$ are mentioned as methods of detecting clinically important alloantibodies that may not be detected on initial screening. The question remains over the circumstances and groups of patients in which these more expensive assays should be used, as the current assays might suffice in most cases.

The patients described were undergoing major operations, and it is doubtful that sufficient matched blood would be available in an emergency outside large centres. We suggested extra matching to reduce the allosensitisation in these patients and so allow blood products matched for the main immunogens only $(\mathrm{ABO}, \mathrm{RhD})$ to be used withou the extra morbidity associated with delayed haemolytic transfusion reactions. It also seemed to us that preventing what is partly an iatrogenic process was in principle better than dealing with the consequences. Alternative treatments for these patients with severe immune suppressor dysfunction also have severe disadvantages in morbidity and cost.

The incidence and consequences of multiple autoimmunity and multiple alloantibodies require further study. These patients are potent "reactors" and the problems caused by multiple allosensitisation can have a profound effect on their clinical management.
Contreras M. Autoimmunity: a risk factor for allosensitisation to blood products? Br Med f 1989;298:457. (18 Februar

2 Wierzbicki AS, Cousins DM. Autoimmunity: a risk factor for allosensitisation to blood products? Br Med f 1989;298:65-6

3 Wallherfechtel MA, Pohl BA, Chaplin H. Alloimmunisation in patients with warm antibodies. Transfusion 1984;24:482-5.

4 Fisher GA. Use of the manual polybrene technique in the routine hospital laboratory. Transfusion 1983;23:152-5.

\section{Screening: the inadequacy of population registers}

SIR,-Drs Ann Bowling and Bobbie Jacobson rightly point out the inaccuracies of family practitioner committee population registers,' but their analyses of the causes and solutions are not so correct.

Firstly, primary care arrangements in the City and Hackney Health Authority are not representative of those of the nation as a whole. This is an inner city area with particularly severe deprivation and an unrepresentative set of general practitioners.

Secondly, until recently family practitioner committees themselves have had to work with antiquated filing systems which have caused various inaccuracies in registration. Recent computerisation and cuts in staffing have often added to the chaos, at least temporarily.

Thirdly, the authors are clearly not familiar with the workings of the Doctors' and Dentists' Review Body, which is well aware of and compensates for list inflation when it makes its recommendations for general practitioners' average net remuneration. Savings are not therefore a reality.

Lastly, the authors state rather glibly that receptionists should routinely check addresses as patients consult the practice. This would be an unacceptable extra burden on what is already a highly pressured job. In our practice patients often do not inform us of their change of address because they have moved out of our practice area but do not want to leave a general practitioner they have known for many years. If asked by a receptionist many would give their old address.

MAREK KOPERSK

Kentish Town Health Centre

London NW5 2AJ

1 Bowling A, Jacobson B. Screening: the inadequacy of population registers. Br Med f 1989;298:545. (4 March.

SIR, - The editorial by Drs Ann Bowling and Bobbie Jacobson about the inaccuracy of population registers' confirms our recent experience of the inaccuracy of the family practitioner committee's register. We were carrying out some geriatric screening in a large rural practice (list size 13910 ) with a monopoly in the area, so our $10 \%$ sample represented $10 \%$ of the local population. We found that $38 \%$ of the over 85 year olds and $18 \%$ of those aged 75 to 84 were incorrectly represented (table).

Percentage of elderly patients incorrectly represented on register of rural practice

Died Moved away Moved into sheltered Total from area accommodation

\begin{tabular}{lrrrr}
\hline Aged $75-84$ & 5 & 6 & 7 & 18 \\
Aged $>85$ & 4 & 13 & 21 & 38 \\
\hline
\end{tabular}

This type of inaccuracy is not limited to the older age groups, as the editorial pointed out. How will it be possible to meet high target percentages for screening-for example, $80 \%$ for cervical screening-if the accuracy of the registers is not greatly improved? If, as the government would like, patients can change doctors easily and quickly the quicker turnover is likely to lead to greater inaccuracies. Areas with a highly mobile population will be financially penalised if the lists with which they are trying to meet their targets contain such large errors. Perhaps they will think that it is just not worth the effort and concentrate their energies on other aspects of primary health care. My example is from an area with a very stable population, and the problem could be far worse elsewhere.

K J KESTIN

Bristol BS9 1SL

1 Bowling A, Jacobsen B. Screening: the inadequacy of population registers. Br Med f 1989;298:545-6. (4 March.)

\section{The illnesses of Elizabeth Barrett Browning}

SIR, - Dr D A B Young valiantly attempts to show that Elizabeth Barrett Browning suffered from pulmonary hypertension and right sided cardiac failure, resulting from poliomyelitis at 15 and subsequent scoliosis. ${ }^{1}$ His evidence is insubstantial.

The descriptions of her teenage illness by the several doctors who attended her, and herself, are unlike those of poliomyelitis. The initial stages of the infection can certainly be painful, but in Elizabeth's case the "suffering was agony" and the pain shifted from site to site, was paroxysmal, and went on for many weeks, perhaps as long as two months. Symptoms suggesting panic attacks were present, with bouts of hyperventilation which terminated in fainting. Neither Elizabeth nor her doctors mentioned any paralysis.

Only severe scoliosis is likely to cause pulmonary hypertension and right sided failure. There are detailed descriptions of Elizabeth's appearance in the letters and diaries of those who met her throughout her life, and although many are unflattering, not a single one even hints at a spinal deformity. To cite an account - probably third or fourth hand-in the New York Home Fournal is hardly good evidence.

Her illness in 1838 , which led to her spending three years in Torquay, was almost certainly pulmonary tuberculosis, and haemoptysis persisted until 1842. She slowly became more active after returning to London, but she remained a recluse, shut up in her room, agoraphobic and terrified of meeting strangers. Only when motivated by Robert Browning did she begin to lead a more normal active life.

Dr Young is wrong when he denies her addiction to opium. She depended on large amounts from 1838 onwards and developed withdrawal symptoms when the dosage was reduced. Even when pregnant with her son and advised to stop the drug she was able to do so only in the eighth month, after much discomfort. In her last despairing years the dosage was steadily increased. Robert Browning's description of her death, "smiling happily," suggests that she may have died as a result of overdosage.

Signs and symptoms of right sided failure were conspicuously absent throughout her life. Her teenage illness was, I believe, anorexia nervosa. She remained anorectic for the rest of her life and at times of crisis became emaciated. The development of tuberculosis on top of anorexia nervosa was not uncommon among Victorian women. In Elizabeth's case pulmonary tuberculosis remitted to a large extent, but the anorexia remained, and when she died she was cachetic.

I have not described the conflict in her mind between her attachment to her father and her love for Robert Browning. She chose Robert Browning but never ceased to grieve for the loss of her father's love, and beneath her illness behaviour was profound depression.

PETER DALLY

London W1N 1PB

1 Young DAB. The illnesses of Elizabeth Barrett Browning. BrMed F 1989;298:439-43. (18 February.) 